\title{
Symposium review: Mechanisms of disruption of fertility by infectious diseases of the reproductive tract*
}

\author{
Robert O. Gilbert† \\ Ross University School of Veterinary Medicine, PO Box 334, Basseterre, St. Kitts and Nevis, West Indies
}

\begin{abstract}
Diseases of postpartum dairy cows impair reproductive processes, resulting in prolonged anestrus, reduced conception, and increased pregnancy attrition, regardless of whether the initial disease precedes insemination (even by many weeks), occurs close to insemination, or follows fertilization. Bacteria and their products activate pattern recognition receptors that respond to pathogen-associated molecular patterns (PAMP). These receptors include toll-like receptors (TLR), nucleotide-binding oligomerization domain (NOD)-like receptors and others, and their activation culminates in upregulation of proinflammatory cytokines such as IL$1 \beta$, IL-18, and tumor necrosis factor- $\alpha$. These may have direct effects on the uterus and conceptus. Importantly, however, these inflammatory mediators, as well as the bacterial products, make their way to the ovary via the general circulation (even from distant sites) or possibly by using the countercurrent vascular mechanism that normally transports endometrial prostaglandin to the ipsilateral ovary. Endotoxin reaches concentrations in follicular fluid that exceed those found in the circulation or even in the infected uterus. Ovarian follicular cells also express TLR and can respond directly to bacterial products including endotoxin, impairing their function. Inflammation is accompanied by increased oxidative stress. The process of oocyte development from activation of primordial oocytes to potential ovulation spans 4 mo. Competence by an oocyte encompasses the ability to undergo not only fertilization but also a complex cytoplasmic maturation that lays the foundation for completion of meiosis at the appropriate time, the transition to mitosis in the zygote, and further development of the conceptus. Oocyte maturation relies on intimate association between cumulus cells and the oocyte, char-
\end{abstract}

\footnotetext{
Received August 25, 2018.

Accepted December 15, 2018.

* Presented as part of the Joint ADSA/SSR Symposium: The Immune-Reproduction Nexus - The Good, the Bad, and the Ugly at the ADSA Annual Meeting, Knoxville, Tennessee, June 2018.

†Corresponding author: RGilbert@rossvet.edu.kn
}

acterized by gap junctions through which molecules of various sizes pass. Signaling also occurs in the oocyteto-cumulus cell direction. Because both granulosa and theca interna cells are capable of responding to inflammatory mediators, with observed alterations in some functions, it seems likely that disturbed ovarian follicular function may contribute to failure of oocytes to become fully competent, even if the insult occurs well before ovulation. Therefore, interruption of normal fertility by uterine infections may be mediated at the level of the uterine environment but the effect on the ovary and oocyte is likely to be even more important. Key words: cow, inflammation, ovary, oxidative stress, uterus

\section{INTRODUCTION}

Establishment of successful pregnancy in cows within a relatively short time after the previous calving is a major driver of productivity and profitability in dairy farming (Britt, 1985). Many of the diseases that afflict dairy cows occur most commonly in the first 2 mo of lactation (Ribeiro et al., 2013; Gilbert, 2016). Unfortunately, periparturient illness of almost any kind mitigates against timely reconception (Ribeiro et al., 2016). Although a great deal of evidence links infectious and noninfectious conditions of the postpartum cow with impaired reproductive performance, our understanding of the specific mechanisms that disrupt reproduction is still rudimentary. This review attempts to summarize the current state of that knowledge, focusing on infectious diseases and especially, but not exclusively, on diseases of the reproductive tract itself. Most data referenced were derived in dairy cattle but some are from investigations in other species, notably rodents and humans. Some of the detrimental effects proposed are speculative but consistent with available evidence. Without insight into the mechanisms linking postpartum disease and impaired reproductive performance, we lack the ability to devise rational interventions to improve reproduction.

The format of this review will be to refer briefly to the literature that established the detrimental effect 
of postpartum disease on subsequent fertility. Because inflammation, broadly speaking, is a common feature of different postpartum conditions, some fundamental aspects of innate immunity and inflammation, as well as oxidative stress, will be explored. Inflammatory mediators and microbial products are capable of reaching the ovary and initiate changes in function of ovarian follicular cells. Several markers of follicular health have been identified and are generally consistent with the hypothesis that inflammation mediates changes in follicular function that diminish the ability of the oocyte to complete meiosis, undergo fertilization, and support development of a conceptus up to blastocyst stage and beyond. Oocytes and other follicular cells are also sensitive to oxidative damage that may deplete the ovarian pool of primordial follicles and damage surviving oocytes sufficiently to render them incapable of fertilization or normal development after fertilization. Although I contend that much of the impaired reproduction that follows postpartum uterine disease is mediated at the level of the ovary, it is clear that uterine disease has residual effects on the ability of the uterus to provide a suitable environment for successful pregnancy that persist even after resolution of obvious signs of active disease. The mechanisms described in this review are summarized in Figure 1.

\section{POSTPARTUM DISEASES DISRUPT SUBSEQUENT REPRODUCTION IN AFFECTED COWS}

Common diseases of dairy cows include retained fetal membranes, metritis, and endometritis (as well as cervicitis), mastitis, lameness and abomasal displacement, clinical hypocalcemia, and ketosis. All of these diseases occur most frequently in the early part of lactation and thus in the period preceding and immediately following insemination (Foditsch et al., 2016; Gilbert and Santos, 2016; Neves et al., 2018). Interestingly, all of these conditions detrimentally affect reproductive performance, whether they are infectious (metritis, endometritis, mastitis, and some cases of lameness) or noninfectious (lameness and abomasal displacement, hypocalcemia, and ketosis). Importantly, diseases of the reproductive tract and those affecting more remote body systems all contribute to reproductive failure. Santos and Ribeiro (2014) reported that virtually all clinical and subclinical disorders of the postpartum cow, not only those of the reproductive tract, delayed onset of cyclicity, reduced pregnancy per insemination, and increased pregnancy wastage. They also showed that postpartum disease was associated with reduced quality of recovered embryos.

An interesting observation is that these diseases and disorders may affect reproductive success, whether

\section{Uterine Disease and Infertility}

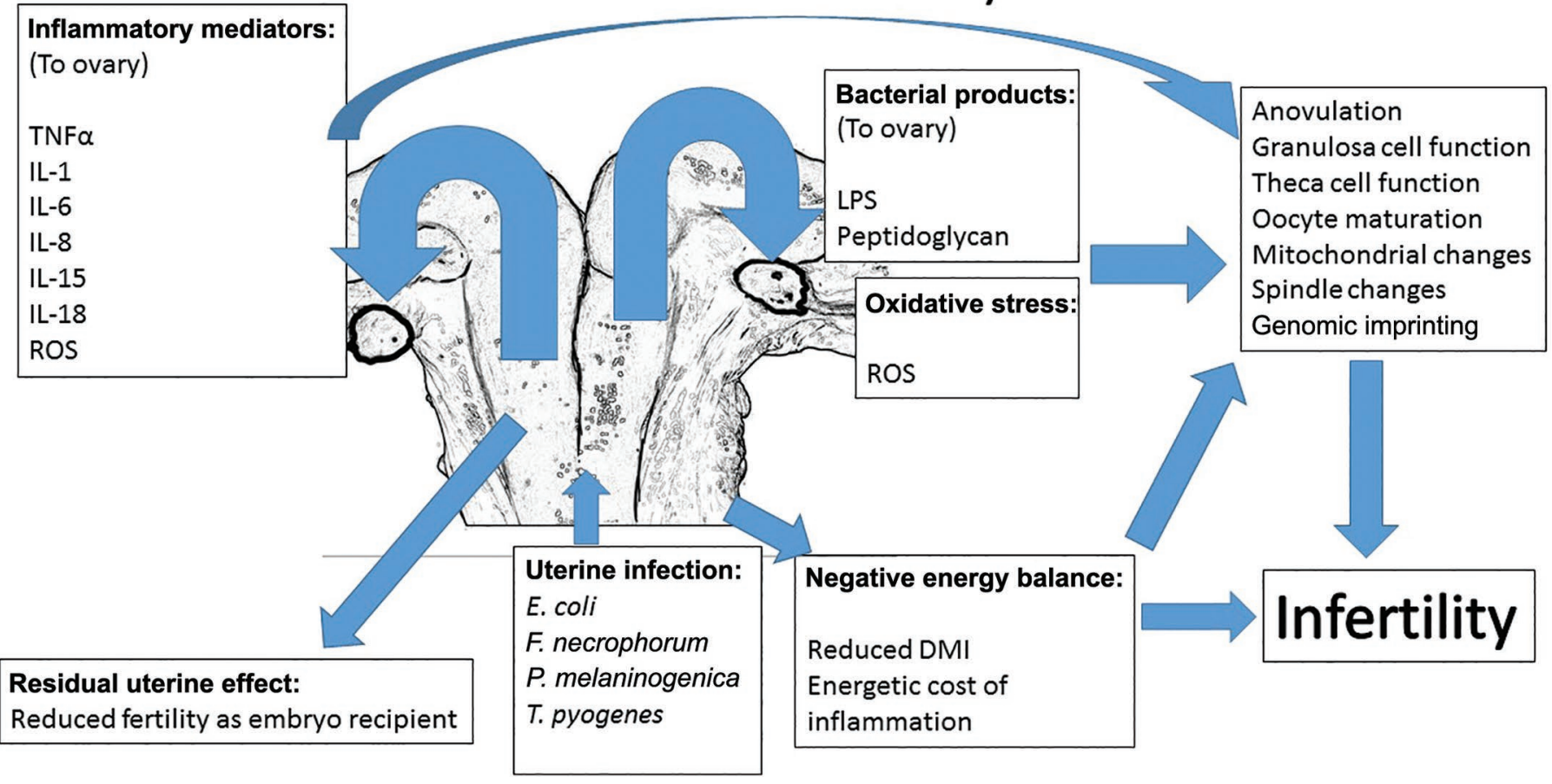

Figure 1. Schematic representation of potential mechanisms whereby uterine infections could contribute to subsequent infertility in dairy cows. $\mathrm{ROS}=$ reactive oxygen species, TNF $\alpha=$ tumor necrosis factor- $\alpha$, E. coli $=$ Escherichia coli, F. necrophorum $=$ Fusobacterium necrophorum; P. melaninogenica $=$ Prevotella melaninogenica, T. pyogenes $=$ Trueperella pyogenes. 
they occur before, close to, or after insemination. For example, it has long been known that mastitis, and especially mastitis attributed to Escherichia coli or other gram-negative organisms, occurring shortly after insemination is associated with reduced pregnancy risk (Wilson et al., 2008), and this has been attributed to a luteolytic effect of endotoxemia (Gilbert et al., 1990). However, cows developing mastitis within the first 45 d postpartum (i.e., before insemination) are almost 3 times more likely to lose a subsequent pregnancy than unaffected cows (Risco et al., 1999). Hertl et al. (2010) examined the effect of clinical mastitis by week of diagnosis and etiology in almost 24,000 cows in 7 herds (including $\sim 55,000$ inseminations) from 6 wk before to $6 \mathrm{wk}$ after insemination. They found no effect of mastitis occurring more than 2 wk before or 5 wk after insemination. For clinical mastitis occurring closer to insemination, the effect varied with both time and etiology. The most severe effects were associated with gram-negative mastitis close to insemination but mastitis of all etiologies significantly reduced pregnancy risk.

Although it is not surprising that diseases of the reproductive tract interfere with reproductive outcomes, it is less intuitive to expect that the effect on reproduction extends beyond the resolution of the disease or that diseases of systems other than the reproductive tract could influence reproduction, even after their resolution, yet this is indeed what is observed. Diseases of the reproductive tract and other body systems of both infectious and noninfectious etiology and occurring before, near, or after insemination all affect reproduction. Furthermore, reproduction may be impaired for a considerable time after resolution of the specific disease.

Successful reproduction requires birth of a single, live, and viable calf within 12 to 14 mo of the previous calving, depending on production system. This, in turn, requires prompt reconception (within a limited and defined period after the previous parturition, often about $100 \mathrm{~d}$ ), with few inseminations (ideally only one), successful maternal recognition of pregnancy, and normal growth and development of embryo and fetus (and placenta). Evidence now suggests that consequences of infectious disease of the reproductive tract can interrupt normal processes in every step of this sequence. Consequences of these infections may include aberrant follicular development and function or failure of ovulation. Oocyte development and maturation may be impaired, leading to fertilization failure or early cessation of development. Damage to the oocyte may result in impaired embryo development and failure of maternal recognition of pregnancy, with loss of the conceptus. Even later embryonic death and fetal death may have their roots in damage inflicted on the oocyte by inflammatory processes.

\section{EFFECTS OF UTERINE DISEASE PERSIST AFTER RESOLUTION OF THE DISEASE ITSELF}

The presence of active uterine disease is inversely proportional to days postpartum (Dubuc et al., 2011; Gilbert and Santos, 2016). The acute and severe postpartum uterine diseases (puerperal metritis) occur mainly during the first $10 \mathrm{~d}$ postpartum and are rarely diagnosed after $14 \mathrm{~d}$. Uterine disease is difficult to diagnose in the period from 2 to 4 wk postpartum because uterine remodeling and an associated physiological form of inflammation are prevalent around $21 \mathrm{~d}$ postpartum and may be indistinguishable from pathologic processes (Gilbert and Santos, 2016). Indeed, the presence of a mucopurulent vaginal discharge at this time is not associated with subsequent reproductive impairment (LeBlanc et al., 2002). Endometritis, either manifesting as purulent vaginal discharge (which may include cervicitis as its cause) or less evident clinically and only detectable by endometrial cytology or biopsy, is prevalent in dairy cows around 4 wk postpartum and its prevalence decreases steadily in the subsequent weeks. The condition appears to be dynamic, however, with spontaneous recovery and recurrence occurring commonly (Dubuc et al., 2011). Active uterine disease appears to be quite unusual at the time cows are actually subject to insemination, but there is clearly a persistent and negative affect on reproduction. For those cows that do have active inflammation at the time of insemination, manifest as visible mucopurulent discharge on the insemination pipette after insemination, pregnancy risk is substantially reduced (Loeffler et al., 1999). The concept that resolution of the active disease does not immediately restore fertility is consistent with the observation that treatment of cows with mucopurulent discharge at the time of insemination does not improve pregnancy risk (Shams-Esfandabadi et al., 2004). Similarly, antibiotic treatment of cows with acute postpartum metritis generally hastens resolution of the clinical disease but does not usually improve subsequent reproduction (Haimerl and Heuwieser, 2014; Lima et al., 2014).

In an elegant series of studies, Ribeiro et al. (2016) examined the effects of several diseases from the day of calving until first insemination. These were retained fetal membranes, metritis, mastitis, lameness, and respiratory and digestive problems. Retained placenta and metritis were grouped as uterine disease. Mastitis, lameness, digestive, and respiratory problems were categorized as non-uterine diseases. All of these diseases, as well as prolonged anovulation and poor body condi- 
tion, reduced pregnancy per insemination. The effect of diseases was independent of, and additive to, anovulation and poor body condition (see also Vieira-Neto et al. (2014). Disease negatively affected pregnancy per breeding on d 45 or 90 and increased the incidence of pregnancy loss from gestation d 45 to term. Uterine and non-uterine diseases had an additive effect in reducing calving per breeding and increasing pregnancy loss. In an effort to investigate the effect of stage of occurrence of disease relative to ovarian follicular development, the authors categorized disease as preantral if it occurred more than $42 \mathrm{~d}$ before insemination and as antral if it occurred in the $42 \mathrm{~d}$ preceding ovulation (Lussier et al., 1987; Scaramuzzi et al., 2011). They also examined the effect of disease occurring after insemination. Disease at all stages reduced pregnancy per insemination and calving per insemination and increased pregnancy loss, meaning that disease many weeks before insemination and remote from the reproductive tract contributed to the diminished likelihood of establishing pregnancy and increased risk of pregnancy failure long after resolution of the disease itself. This observation is reminiscent of what has become known as the "Britt Hypothesis." In 1992, Jack Britt postulated that the carryover effect of periparturient negative energy balance on later reproduction might be attributable to the fact that ovarian follicles develop over a long period, and that follicles developing during periods of a hostile metabolic environment sustained lasting damage that diminished the capacity of the associated oocyte to participate in the development of a robust, viable conceptus (Britt, 1992). Indeed, there is a long interval between recruitment from the resting pool of primordial oocytes and eventual ovulation - a period of some $130 \mathrm{~d}$ (Scaramuzzi et al., 2011), and the latent effect of early postpartum disease had been recognized earlier (Oltenacu et al., 1983).

Although effects on the ovarian follicle and associated oocyte are probably of major importance, there are clearly persistent uterine effects as well. Ribeiro et al. (2016) went on to examine the effect of postpartum disease on reproduction when insemination was replaced by embryo transfer, in effect bypassing any effect on the ovary or uterine tubes. Interestingly, disease before breeding diminished the ability to maintain pregnancy, regardless of manner of breeding (AI or embryo transfer). This was true for both non-uterine and uterine diseases. Overall, the proportion of cows pregnant at 45 $\mathrm{d}$ or calving was numerically but not statistically higher for cows bred by embryo transfer, consistent with the hypothesis that prepartum disease affects both the uterus and ovary and that the effects may be additive. This concept requires further investigation.

\section{UTERINE DISEASE AFFECTS OVARIAN FOLLICULAR FUNCTION}

The causative bacteria involved in bovine uterine disease have been investigated for decades using traditional culture-dependent methods (Griffin et al., 1974a,b; Sheldon et al., 2002, 2004; Williams et al., 2007; Gilbert and Santos, 2016); more recently, metagenomic techniques have been applied (Santos et al., 2011; Machado et al., 2012). Although the complexity of the uterine microbiome revealed by metagenomics methods is yet to be fully understood, it seems that a relatively small spectrum of bacterial pathogens is consistently responsible for a wide range of clinically divergent disease manifestations. Chief among these are Escherichia coli, Trueperella pyogenes, and the gram-negative anaerobes Prevotella melaninogenica and Fusobacterium necrophorum (Sheldon et al., 2002; Bicalho et al., 2012; Machado et al., 2012; Gilbert and Santos, 2016). What has emerged from metagenomic investigation is that the gram-negative anaerobes, always thought to be important in pathogenesis of uterine disease, are much more numerous than the other pathogens, further emphasizing their pivotal role in mediating metritis and endometritis (Sicsic et al., 2018). Specific strains of Escherichia coli possessing specific virulence factors appear to have an affinity for the postpartum uterus and to mediate disease, even though they are rarely present once active disease is diagnosed. During active clinical disease (metritis or endometritis), the gram-negative anaerobes $F$. necrophorum and $P$. melaninogenica are of major importance, as is the gram-positive T. pyogenes. These organisms all express well-characterized virulence factors that contribute to their role in mediating uterine disease (Sheldon et al., 2010; Bicalho et al., 2012; Gilbert and Santos, 2016). A common feature of the gram-negative organisms is production of endotoxin (lipopolysaccharide, LPS).

The critical link between uterine disease and infertility is inflammation. The innate immune system responds immediately to pathogens (or intrinsic tissue damage) by recognizing conserved molecular motifs common to infectious pathogens or tissue damage. These pattern recognition receptors (PRR) are germline encoded, which means they are expressed and functional without prior exposure to pathogens (Bryant and Fitzgerald, 2009). Several families of PRR have been identified. These include toll-like receptors (TLR), nucleotidebinding oligomerization domain (NOD)-like receptors family, C-type lectin receptors (CLR), RIG-like helicases (RLR), and cytosolic DNA receptors (Bryant and Fitzgerald, 2009). These sensing molecules trigger molecular pathways that culminate in the production 
of inflammatory cytokines and the propagation of an inflammatory response to curb, control, or eliminate the danger. The pattern recognition molecules are present on the cell surface or in specific organelles or the cytosol, depending on the molecules they detect, so the molecular pathway may begin at different locations. For example, the cell-surface molecules (e.g., TLR1, 2, $4,5,6,10$, and 11) detect bacterial surface components, whereas TLR3, 7, 8, and 9 are found on the inner surface of endosomes, where they interact with nucleic acid ligands. The NLR family members are cytosolic and respond to a variety of endogenous and exogenous molecules. The ligand recognition domains of TLR and (NOD)-like receptors consist of leucine-rich repeats (LRR). The effector domains of these receptors are varied, but all essentially result in upregulation of inflammatory cytokines such as IL-1 $\beta$, IL-12, IL-18, tumor necrosis factor $\alpha(\mathbf{T N F} \boldsymbol{\alpha})$, IFN $\gamma$, or granuolocyte-macrophage colony stimulating factor (GM-CSF) via stimulation of nuclear factor $(\mathrm{NF}) \kappa \mathrm{B}$ and mitogenactivated kinase (MAPK), c-Jun N-terminal associated kinase (JNK), or p38. The interleukins are typically produced in pro-forms, and cleaved to the active molecule via caspase- 1 produced by molecular complexes known as "inflammasomes" (Bryant and Fitzgerald, 2009; Monie et al., 2009).

Pattern recognition receptors, including TLR1 to 10, have all been identified in the bovine uterus (Davies et al., 2008), meaning that a range of pathogens or other forms of tissue damage can result in local production of inflammatory mediators. Importantly, the bacterial products themselves (such as LPS, also known as endotoxin, or peptidoglycan) or the inflammatory mediators they provoke may reach the ovary (Herath et al., 2007; Magata et al., 2014a,c, 2015; Magata and Shimizu, 2017). It seems likely that the countercurrent exchange mechanism, whereby endometrial prostaglandins are directly transported to the ipsilateral ovary using the intimate association between the ovarian branch of the uterine vein and the ovarian artery (Mapletoft et al., 1975, 1976a,b; Mapletoft and Ginther, 1975), may preferentially transport these active molecules to the ovary, where they may be found in follicular fluid, although this hypothesis has never been tested. Lipopolysaccharide activates TLR4. Bacterial pathogens have also been identified within human follicular fluid (Pelzer et al., 2013). Expression of TLR1 to 10 by bovine granulosa cells has been confirmed (Price et al., 2013). Functional integrity of pathways initiated by binding of TLR2 and TLR4 in bovine granulosa cells, leading to impaired steroidogenesis, has been demonstrated (Herath et al., 2007). In addition to being activated by pathogens or their products, ovarian TLR may play a role in normal function (e.g., ovulation) and their expression may be altered in some disease states (Gu et al., 2016).

\section{OXIDATIVE STRESS CONTRIBUTES TO INFERTILITY}

Oxygen is essential to mammalian life, with oxidative metabolism providing a major source of energy. Reactive oxygen species (ROS) are an inevitable by-product of oxidative metabolism, and antioxidant mechanisms exist to limit tissue damage. Most ROS result from leakage of electrons from the mitochondrial respiratory chain (electron transport chain; Fujii et al., 2005). Biologically important ROS include superoxide anion, hydroxyl radical, peroxyl radical, alkoxyl, and hydroperoxyl. A characteristic of ROS is that they are highly reactive and unstable because of the presence of an unpaired electron. They can become stable by accepting electrons from other molecules. In this way, they can initiate chain reactions and damage lipids, nucleic acids, proteins, and carbohydrates. Enzymatic antioxidants include superoxide dismutase, glutathione peroxidase, catalase, and glutathione reductase, which catalyze the decomposition of ROS to water and alcohol. Nonenzymatic antioxidants include many nutrients such as antioxidative vitamins, polyphenols, and some minerals (Lu et al., 2018). Importantly, oxidative processes play an important role in normal reproductive physiology, such as disulfide bond formation in sperm nuclei and in ovulation (Fujii et al., 2005). However, ROS production is increased in pathological conditions and may exceed the capacity of protective mechanisms, potentially resulting in tissue damage. Inflammatory processes (aimed at eliminating noxious agents and initiating tissue repair) such as increased blood flow, production of inflammatory cytokines, and recruitment of leukocytes and macrophages, result in excessive ROS production and oxidative stress, with specific production of antimicrobial molecules (Valacchi et al., 2018).

Oxidative stress, specifically in prophase of meiosis I, results in disordered chromosome segregation. Importantly, mammalian oocytes are suspended at this stage of nuclear development from birth until preovulatory resumption of meiosis, suggesting that the entire reserve pool of oocytes could suffer damage from prolonged or repeated oxidative stress. Indeed, the cumulative effects of oxidative stress are believed to underlie deterioration in oocyte quality as a component of reproductive aging in many species (Perkins et al., 2016). It seems plausible that a prolonged period of inflammation in the postpartum period could inflict damage on developing oocytes and the resting oocyte pool via oxidative insult, even affecting DNA, resulting in chronically diminished fertility (Da Broi et al., 2018b). 
Apart from direct damage inflicted on oocytes by oxidative stress, granulosa cell function may be impaired, adding indirectly to functional impairment of associated oocytes. Evidence of oxidative stress in granulosa cells recovered along with oocytes for human in vitro fertilization was more severe for oocytes that failed to become fertilized or develop to blastocyst stage (Ávila et al., 2016; Lai et al., 2018), indicating that oxidative stress, at least at the antral stage of follicular development, has a detrimental effect on the follicle and oocyte.

Oxidative stress also takes its toll on uterine function, and measures of oxidative stress in uterine fluid aspirated from women before transfer of in vitro fertilized embryos were correlated with pregnancy outcomes. Women in whom clinical pregnancies were established had less evidence of uterine oxidative damage than those in whom in vitro fertilization was unsuccessful in establishing pregnancy (Rahiminejad et al., 2016).

\section{INFLAMMATION DEPLETES THE POOL OF PRIMORDIAL FOLLICLES (OVARIAN RESERVE)}

Not only does inflammation and associated oxidative stress damage oocytes in ways that prevent successful fertilization and further development, mounting evidence indicates that these processes can actually deplete the pool of primordial follicles by prematurely activating them. Once activated, follicles are committed to develop until atresia or ovulation.

Administration of LPS to neonatal rodents results in acute loss of primordial follicles (Bromfield and Sheldon, 2013; Sominsky et al., 2015; Fuller et al., 2017), an observation duplicated in vitro using bovine ovarian cortex (Bromfield and Sheldon, 2013). During inflammatory processes activation of phosphoinositol 3 kinase (PI3K) results in conversion of phosphoinositol diphosphate to phosphoinositol triphosphate, with activation of protein kinase $\mathrm{B}$ (PKB, also known as AKT), which happens to be the pathway by which quiescent primordial follicles are activated to leave the resting pool and embark on development to ultimate atresia or ovulation (Bromfield and Sheldon, 2013). This observation seems to have clinical relevance because women with chronic pelvic inflammation experience depletion of the ovarian reserve (Cui et al., 2016). Depletion of primordial follicles not only shortens reproductive lifespan, but also may affect fertility at normal reproductive age. Antral follicular count is highly repeatable within individual cows, and is correlated with the overall number of healthy follicles and oocytes (Burns et al., 2005; Ireland et al., 2008). Furthermore, cows with high numbers of antral follicles (and therefore greater ovarian reserve) generally exhibit higher fertility (Ireland et al., 2009,
2011). Therefore, depletion of the overall number of primordial follicles may be mediated by inflammation and have a permanent detrimental effect on fertility of cows.

\section{UTERINE DISEASE INCREASES THE RISK OF ANOVULATION}

Anovulation by the end of the voluntary waiting period has been found to be associated with a reduced conception rate per cycle (Gümen et al., 2003; Galvão et al., 2004; Santos et al., 2004a), longer time to first insemination and more days open (Walsh et al., 2007), and also with increased pregnancy failure (Gümen et al., 2003; Santos et al., 2004a; Sterry et al., 2006).

Cows that fail to ovulate by the end of the voluntary waiting period (60 to $65 \mathrm{~d}$ postpartum) have lower pregnancy rates than ovulatory cows and are at higher risk of embryonic loss. Galvão et al. (2010) reported that cows ovulating before $21 \mathrm{~d}$ postpartum had greater hazard of pregnancy than those ovulating for the first time between 21 and 49 d postpartum, which, in turn, performed better than those ovulating for the first time after 49 d postpartum. Dubuc et al. (2012) reported that, in their study population of high-producing dairy cows, $28 \%$ of the cows ovulated by $21 \mathrm{~d}$ postpartum, $56 \%$ by $35 \mathrm{~d}, 74 \%$ by $49 \mathrm{~d}$, and $21 \%$ remained anovulatory by $63 \mathrm{~d}$ postpartum. Those authors also reported that the effects of anovulation were more severe in cows in third or greater lactation relative to cows in their first or second lactation (Dubuc et al., 2012). Major risk factors for anovulation or delayed first ovulation are negative energy balance before and after parturition, inflammation indicated by the acute phase protein haptoglobin in the first week postpartum, and presence of cytological endometritis (Dubuc et al., 2012; Cheong et al., 2016; Santos et al., 2016); milk yield has little effect on anovulation. Although both endometritis and anovulation exert a detrimental effect on reproduction, these effects appear to be independent and additive (Vieira-Neto et al., 2014).

One mechanism connecting anovulation with uterine disease is the effect of LPS on follicular function. It is clear that endotoxin can reach the follicle and that the follicular cells express TLR4, enabling them to respond to LPS, which causes decreased steroidogenesis (Herath et al., 2007; Magata et al., 2014a,b,c). Reduced synthesis of androstenedione and estradiol is a feature of anovulatory postpartum follicles (Cheong et al., 2016, 2017). The association of uterine disease with smaller, slower growing follicles (Sheldon et al., 2002), combined with reduced steroidogenesis, contribute to prolonged postpartum anovulation, itself a cause of infertility (Santos et al., 2016). 
A major contributor to anovulation is negative energy balance (Butler, 2001, 2003). Negative energy balance in postpartum cows is associated with reduced $\mathrm{LH}$ pulse frequency, impaired steroidogenesis, and anovulation, contributing to reduced fertility (Butler, 2000). There is a metabolic cost to activating the immune system. In an informative experiment, Kvidera et al. (2016) infused fasted steers with BW of approximately $150 \mathrm{~kg}$ with a low dose of LPS $(1.5 \mu \mathrm{g} / \mathrm{kg})$ and measured the amount of glucose required to maintain euglycemia for the ensuing $12 \mathrm{~h}$ (beginning the infusion at $3 \mathrm{~h}$ after injection of the LPS bolus). They found that approximately 500 $\mathrm{g}$ of glucose was required, implying that the cost of activating the immune system in this way amounted to $1 \mathrm{~kg}$ of glucose per animal per day. This is equivalent to approximately $1 \mathrm{~g} / \mathrm{kg}$ of $\mathrm{BW}^{0.75}$ per hour, almost 100 $\mathrm{kcal} / \mathrm{kg}$ of $\mathrm{BW}^{0.75}$ per day or $13 \mathrm{Mcal} / \mathrm{d}$ for a $700-\mathrm{kg}$ cow. Acute metritis is associated with reduced DMI (Gilbert, 2016), and the energetic cost of inflammation is likely to exacerbate the effects on negative energy balance. Metabolic indicators of negative energy balance such as hyperketonemia and increased circulating concentrations of nonesterified fatty acids (NEFA) are associated with metritis (Abdelli et al., 2017) and these parameters are, in turn, associated with reduced fertility (Barletta et al., 2017; Bicalho et al., 2017). Not only are elevated blood concentrations of $\beta$-hydroxybutyric acid and NEFA indicators of negative energy balance, the metabolites are themselves potentially detrimental to oocyte health and fertilization (Sutton-McDowall et al., 2016). Therefore, one pathway by which uterine disease could affect anovulation and subsequent infertility is by exacerbating negative energy balance.

\section{A MAJOR EFFECT OF UTERINE DISEASE IS SUBSEQUENT FAILURE OF FERTILIZATION}

In a study aimed at elucidating effects of selenium source on postpartum reproductive parameters, Cerri et al. (2009) reported that single embryo or oocyte recovery from cows previously diagnosed with cytologic endometritis at $5 \mathrm{~d}$ after ovulation was as successful as that from unaffected cows but the fertilization rate tended to be lower. Subsequently, a similar observation of reduced fertilization rate but unaltered embryo or oocyte recovery rate in cows previously suffering from endometritis was published for superovulated cows (Carvalho et al., 2013). Although both of these studies were focused on other variables, they jointly show that one significant effect of endometritis is failure of fertilization, even after resolution of the active inflammation. Subsequently, a careful study indicated that although uterine and extrauterine disease of postpartum cows influenced reproduction at different stages, the detrimental effect on fertilization (cleavage) was specific for uterine disease (Ribeiro et al., 2016). Collectively, these studies provide important evidence that infertility following uterine disease is likely mediated, at least in large part, at the level of the ovary, rather than the more intuitive conclusion that endometritis simply creates a hostile uterine environment. The experiments described above cannot exclude a role for the uterus or uterine tube in interfering with fertilization. However, the observation that LPS impairs meiotic progression (Magata and Shimizu, 2017) and that a similar dysfunction could be induced by exposure of bovine oocytes to follicular fluid from women with mild endometriosis (Da Broi et al., 2014) supports the concept that inflammatory disorders may impair fertilizability at the level of the developing oocyte.

In 1992, Jack Britt suggested that metabolic stress, in the form of negative energy balance, could detrimentally affect oocyte development and competence in dairy cows. Pointing to the long period of oocyte development from activation of primordial follicles to ovulation, he argued that the hostile environment experienced by the developing oocyte had lasting negative consequences (Britt, 1992). Direct evidence of severe and irreversible damage to oocytes during development is accumulating. For example, obese mice experience infertility and one mechanism is that oocyte development is impeded resulting in aberrant spindle formation. Reversal of the obesity by diet alone or by exercise does not eliminate the spindle disorders (Reynolds et al., 2015; Boudoures et al., 2016). The mechanism of obesity-related oocyte damage is not fully elucidated and may involve oxidative damage and abnormal lipid accumulation in the oocyte. However, this example demonstrates that oocytes are subject to damage during development and that this damage may persist after the inciting cause is removed. It is feasible, but still hypothetical, that inflammatory and oxidative effects on oocytes similarly result in persistent damage.

Inflammatory products and mediators may be found in the follicular environment. It is clear that endotoxin (LPS) is not only found in follicular fluid but that its concentration in follicular fluid is related to the severity of uterine disease (Herath et al., 2007), and that follicular fluid concentrations may exceed contemporary blood concentrations (Magata et al., 2015; Cheong et al., 2017). Although LPS in follicular fluid may detrimentally affect oocytes (Magata and Shimizu, 2017), it is not yet understood whether LPS affects oocyte competence if the exposure occurs in preantral stages of development. It seems plausible, but remains to be shown, that granulosa and theca cells, known to express TLR (Herath et al., 2007; Magata et al., 2014b; Gu et al., 2016) respond to LPS (and indeed other PAMP) 
in earlier stages of development, potentially disrupting the intricate communication between oocyte and cumulus cells that is necessary for competent oocyte development.

To understand the potential effects of inflammation on oocyte competence, we first need to examine the concept of "competence." In its narrowest sense, it has been taken to mean the ability to resume meiosis and complete fertilization (Albertini, 2018). However, it is now clear that oocyte quality contributes to early and even later development of the conceptus (Eppig et al., 1994; Eppig, 1996). The importance of oocyte quality in fertilization failure was first emphasized by Swain and Pool (2008), who pointed out the long period of oocyte maturation, beginning during oocyte growth and intimately linked to follicular development, and stressed the multiple potential influences on fertilization potential and developmental competence. Mature oocytes are essentially transcriptionally silent; all required mRNA for fertilization and postfertilization processes, up to the stage of activation of the zygote genome, must be packaged into the preovulatory oocyte. Their origin is largely from the surrounding cumulus cells, emphasizing again the importance of the intimate association between oocyte and cumulus (Da Broi et al., 2018a). It is now clear that "oocyte competence" refers to much more than the ability to be fertilized and complete meiosis. Oocyte quality is an important factor required for successful development to blastocyst stage, and even into the fetal stage of development, if not beyond (Vannuccini et al., 2016; Albertini, 2018; Da Broi et al., 2018a).

The process of folliculogenesis begins in fetal life. Mitotically active oogonia containing c-kit interact with cells of the mesonephros containing the kit ligand to form ovigerous cords (Scaramuzzi et al., 2011). In cattle, and presumably other mammals, oogonia form tight junctions with the surrounding mesonephric cells that become pre-granulosa cells (Sawyer et al., 2002), facilitating intimate communication between oocyte and cumulus cells for the entire duration of folliculogenesis. Primordial follicles are activated from the resting pool in a continuous process beginning in fetal life and continuing through adult life, with or without ovulation. Once activated, follicles continue to grow until they ovulate or undergo atresia (Scaramuzzi et al., 2011). In cattle, the period from activation to ovulation is as long as $130 \mathrm{~d}$. Throughout this process, the developing oocyte is metabolically active, expressing an array of genes in sequence, depending on stage of development, in contrast to the previous view that primordial oocytes were quiescent (Scaramuzzi et al., 2011). Oocyte growth and development is intimately linked to the mutually dependent relationship with granulosa and theca cells and particularly with the cumulus cells. During this process, the oocyte first acquires meiotic competence and then developmental competence. The bidirectional communication between oocyte and cumulus cells is complex and not fully understood, but signaling molecules of the transforming growth factor (TGF)- $\beta$ superfamily, particularly growth differentiation factor 9 (GDF9) and bone morphogenetic protein 15 (BMP15, also known as GDF9b), are critical. Expression of BMP15 and of GDF9 in other organs is influenced by inflammation (Chen et al., 2016; Fuller et al., 2017), and it is reasonable to assume that inflammatory processes in the ovary could affect the delicate interaction between oocyte and cumulus, with negative consequences.

Evidence of inflammatory products in follicular fluid (inflammatory cytokines such as IL-1 $\beta$, IL-6, IL-18, $\mathrm{TNF} \alpha$, and $\mathrm{IFN} \gamma$ ) is associated with reduced success in human in vitro fertilization (Da Broi et al., 2018a). The ability of preantral follicles to respond to inflammation (and specifically to LPS) by premature activation of quiescent primordial follicles has been referred to above. Similarly, it is clear that LPS impairs function of granulosa and theca cells at the antral stage of follicular development. Although direct evidence is lacking, effects of LPS during the intervening stages of development seem likely. Effects on DNA (segregation and spindle formation) may result in fertilization failure or in early demise of the conceptus.

During in vitro bovine embryo production, exposure of maturing oocytes to nitric oxide, LPS, or TNFo generally does not affect fertilization (cleavage) but either reduces development to blastocyst stage or results in increased blastocyst apoptosis (reviewed in Gilbert, 2011). Similarly, maturation of oocytes in an environment of oxidative stress did not influence cleavage but reduced development to blastocyst stage (Goodale et al., 2017). Given that these in vitro studies necessarily use rather extreme conditions, it is plausible that naturally occurring, inflammation-associated insults could result in more subtle damage evident even later in development.

\section{UTERINE DISEASE CAUSES PREGNANCY ATTRITION}

Loss of established pregnancy between d 28 and 60 after ovulation is common in dairy cows (Santos et al., 2004b). Disease in the postpartum period significantly increases the risk of pregnancy loss (Ribeiro et al., 2013). Although the prevalence of diagnosed pregnancy loss (after positive diagnosis) is high, the greatest incidence of embryonic death probably precedes pregnancy diagnosis by current methods (Diskin et al., 2011; Wilt- 
bank et al., 2016). Incidence of disease before insemination reduced the proportion of high-quality morulae recovered at 5 or $6 \mathrm{~d}$ after insemination (Ribeiro et al., 2016). Although both uterine and non-uterine disease affected embryo quality, uterine disease specifically reduced the percentage of oocytes that cleaved. Considering a slightly later stage of pregnancy (around 15 $\mathrm{d}$ after ovulation), the same authors found no difference in pregnancy rate between cows that did and did not experience disease before insemination, but found that previously diseased cows had small elongating conceptuses and lower intrauterine concentrations of IFN- $\tau$ (Ribeiro et al., 2016), suggesting that maternal recognition of pregnancy may be more likely to fail in previously diseased cows. Consistent with this observation, the authors reported that maternal transcript expression for interferon-stimulated genes (ISG15, RTP4) was decreased in previously diseased cows. Previous disease was also associated with lower circulating concentrations of progesterone (Ribeiro et al., 2016), which might be attributable to effects of inflammation on granulosa and theca cell function (Sheldon et al., 2009). Ribeiro et al. (2016) examined the transcriptome of Day 16 embryos recovered from cows with and without disease and identified 35 differentially expressed genes. Major upstream regulators of changes in transcript were LPS, $\mathrm{TNF} \alpha$, and IFN $\gamma$, providing powerful evidence that inflammatory mediators to which the developing oocyte is exposed may have long-term deleterious effects on a subsequent conceptus.

\section{UTERINE EFFECTS OF INFLAMMATION}

Although much of the infertility that follows uterine disease can be attributed to ovarian effects and lasting damage to oocytes, it is clear that some of the consequences of uterine disease are mediated at the level of the uterus. Evidence for this comes from the observation that when previously diseased cows are used as embryo recipients, establishment of diagnosed pregnancy is reduced and rate of loss of pregnancy is increased relative to that of previously healthy cows (Ribeiro et al., 2016). One potential mechanism might be persistent oxidative stress in the uterus. Rahiminejad et al. (2016) reported that pregnancy rates were lower in human IVF patients with markers of oxidative damage in uterine fluid at the time of embryo transfer. Other explanations include inappropriate ability of the endometrium to engage in the required cross talk with the conceptus for successful establishment of pregnancy, as has been observed in other forms of infertility (Moraes et al., 2018). The uterus may be impaired secondary to altered steroid synthesis resulting from inflammation or inflammatory mediators and oxidants may persist in the uterus interfering with subsequent establishment of pregnancy (Vannuccini et al., 2016). It is clear that the uterus deserves further attention to elucidate mechanisms for persistent detrimental effects on establishment and maintenance of pregnancy after uterine disease.

\section{OTHER CONSIDERATIONS}

It is possible that immune dysfunction persists after fertilization. Bovine embryos usually have low expression of major histocompatibility complex (MHC1) genes but expression is increased in embryos from cows with a history of previous disease, making these embryos more susceptible to immune attack (Ribeiro et al., 2016). This review has not considered mechanisms such as gene imprinting (differential methylation) or the role of non-encoding RNA molecules, which may turn out to be highly significant. Over 200 microRNAs have been identified in follicular fluid of women, and the microRNA profile is altered in women with pelvic inflammatory disease (Dumesic et al., 2015).

\section{CONCLUSIONS}

Uterine disease in dairy cows is common and affects fertility by mediating anovulation and damaging developing oocytes in ways that prevent fertilization or interfere with normal development. There also appear to be lasting detrimental effects on uterine function, resulting in failure of maternal recognition of pregnancy and pregnancy failure. These effects appear to be mediated by bacterial products and endogenous inflammatory mediators, as well as by associated oxidative stress. Improved understanding of these pathways may yield novel management approaches to improve fertility of dairy cows.

\section{REFERENCES}

Abdelli, A., D. Raboisson, R. Kaidi, B. Ibrahim, A. Kalem, and M. Iguer-Ouada. 2017. Elevated non-esterified fatty acid and beta-hydroxybutyrate in transition dairy cows and their association with reproductive performance and disorders: A meta-analysis. Theriogenology 93:99-104.

Albertini, D. F. 2018. Naturing and nurturing the competent oocyte: It's all in the niche. J. Assist. Reprod. Genet. 35:733-734.

Ávila, J., R. Gonzalez-Fernandez, D. Rotoli, J. Hernandez, and A. Palumbo. 2016. Oxidative stress in granulosa-lutein cells from in vitro fertilization patients. Reprod. Sci. 23:1656-1661.

Barletta, R. V., M. Maturana Filho, P. D. Carvalho, T. A. Del Valle, A. S. Netto, F. P. Renno, R. D. Mingoti, J. R. Gandra, G. B. Mourao, P. M. Fricke, R. Sartori, E. H. Madureira, and M. C. Wiltbank. 2017. Association of changes among body condition score during the transition period with NEFA and BHBA concen- 
trations, milk production, fertility, and health of Holstein cows. Theriogenology 104:30-36.

Bicalho, M. L., V. S. Machado, G. Oikonomou, R. O. Gilbert, and R. C. Bicalho. 2012. Association between virulence factors of Escherichia coli, Fusobacterium necrophorum, and Arcanobacterium pyogenes and uterine diseases of dairy cows. Vet. Microbiol. 157:125-131.

Bicalho, M. L., E. C. Marques, R. O. Gilbert, and R. C. Bicalho. 2017. The association of plasma glucose, BHBA, and NEFA with postpartum uterine diseases, fertility, and milk production of Holstein dairy cows. Theriogenology 88:270-282.

Boudoures, A. L., M. Chi, A. Thompson, W. Zhang, and K. H. Moley. 2016. The effects of voluntary exercise on oocyte quality in a dietinduced obese murine model. Reproduction 151:261-270.

Britt, J. H. 1985. Enhanced reproduction and its economic implications. J. Dairy Sci. 68:1585-1592.

Britt, J. H. 1992. Impacts of early postpartum metabolism on follicular development and fertility. Bovine Proc. 24:39-43.

Bromfield, J. J., and I. M. Sheldon. 2013. Lipopolysaccharide reduces the primordial follicle pool in the bovine ovarian cortex ex vivo and in the murine ovary in vivo. Biol. Reprod. 88:98.

Bryant, C., and K. A. Fitzgerald. 2009. Molecular mechanisms involved in inflammasome activation. Trends Cell Biol. 19:455-464.

Burns, D. S., F. Jimenez-Krassel, J. L. Ireland, P. G. Knight, and J. J. Ireland. 2005. Numbers of antral follicles during follicular waves in cattle: Evidence for high variation among animals, very high repeatability in individuals, and an inverse association with serum follicle-stimulating hormone concentrations. Biol. Reprod. 73:54-62.

Butler, W. R. 2000. Nutritional interactions with reproductive performance in dairy cattle. Anim. Reprod. Sci. 60-61:449-457.

Butler, W. R. 2001. Nutritional effects on resumption of ovarian cyclicity and conception rate in postpartum dairy cows. Br. Soc. Anim. Sci. Occ. Publ. No. 26. 1:133-145.

Butler, W. R. 2003. Energy balance relationships with follicular development, ovulation and fertility in postpartum dairy cows. Livest. Prod. Sci. 83:211-218.

Carvalho, P. D., A. H. Souza, R. Sartori, K. S. Hackbart, A. R. Dresch, L. M. Vieira, P. S. Baruselli, J. N. Guenther, P. M. Fricke, R. D. Shaver, and M. C. Wiltbank. 2013. Effects of deep-horn AI on fertilization and embryo production in superovulated cows and heifers. Theriogenology 80:1074-1081.

Cerri, R. L., H. M. Rutigliano, F. S. Lima, D. B. Araujo, and J. E. Santos. 2009. Effect of source of supplemental selenium on uterine health and embryo quality in high-producing dairy cows. Theriogenology 71:1127-1137.

Chen, C., L. Shi, Y. Li, X. Wang, and S. Yang. 2016. Disease-specific dynamic biomarkers selected by integrating inflammatory mediators with clinical informatics in ARDS patients with severe pneumonia. Cell Biol. Toxicol. 32:169-184.

Cheong, S. H., O. G. Filho, V. A. Absalon-Medina, S. H. Pelton, W. R. Butler, and R. O. Gilbert. 2016. Metabolic and endocrine differences between dairy cows that do or do not ovulate first postpartum dominant follicles. Biol. Reprod. 94:18.

Cheong, S. H., O. G. Sa Filho, V. A. Absalon-Medina, A. Schneider, W. R. Butler, and R. O. Gilbert. 2017. Uterine and systemic inflammation influences ovarian follicular function in postpartum dairy cows. PLoS One 12:e0177356.

Cui, L., Y. Sheng, M. Sun, J. Hu, Y. Qin, and Z. J. Chen. 2016. Chronic pelvic inflammation diminished ovarian reserve as indicated by serum anti-Mullerian hormone. PLoS One 11:e0156130.

Da Broi, M. G., V. S. I. Giorgi, F. Wang, D. L. Keefe, D. Albertini, and P. A. Navarro. 2018a. Influence of follicular fluid and cumulus cells on oocyte quality: Clinical implications. J. Assist. Reprod. Genet. 35:735-751.

Da Broi, M. G., A. A. Jordao Jr., R. A. Ferriani, and P. A. Navarro. 2018b. Oocyte oxidative DNA damage may be involved in minimal/mild endometriosis-related infertility. Mol. Reprod. Dev. $85: 128-136$

Da Broi, M. G., H. Malvezzi, C. C. Paz, R. A. Ferriani, and P. A. Navarro. 2014. Follicular fluid from infertile women with mild en- dometriosis may compromise the meiotic spindles of bovine metaphase II oocytes. Hum. Reprod. 29:315-323.

Davies, D., K. G. Meade, S. Herath, P. D. Eckersall, D. Gonzalez, J. O. White, R. S. Conlan, C. O'Farrelly, and I. M. Sheldon. 2008. Tolllike receptor and antimicrobial peptide expression in the bovine endometrium. Reprod. Biol. Endocrinol. 6:53.

Diskin, M. G., M. H. Parr, and D. G. Morris. 2011. Embryo death in cattle: An update. Reprod. Fertil. Dev. 24:244-251.

Dubuc, J., T. F. Duffield, K. E. Leslie, J. S. Walton, and S. J. Leblanc. 2011. Randomized clinical trial of antibiotic and prostaglandin treatments for uterine health and reproductive performance in dairy cows. J. Dairy Sci. 94:1325-1338.

Dubuc, J., T. F. Duffield, K. E. Leslie, J. S. Walton, and S. J. LeBlanc. 2012. Risk factors and effects of postpartum anovulation in dairy cows. J. Dairy Sci. 95:1845-1854.

Dumesic, D. A., D. R. Meldrum, M. G. Katz-Jaffe, R. L. Krisher, and W. B. Schoolcraft. 2015. Oocyte environment: Follicular fluid and cumulus cells are critical for oocyte health. Fertil. Steril. 103:303-316

Eppig, J. J. 1996. Coordination of nuclear and cytoplasmic oocyte maturation in eutherian mammals. Reprod. Fertil. Dev. 8:485-489.

Eppig, J. J., R. M. Schultz, M. O'Brien, and F. Chesnel. 1994. Relationship between the developmental programs controlling nuclear and cytoplasmic maturation of mouse oocytes. Dev. Biol. 164:1-9.

Foditsch, C., G. Oikonomou, V. S. Machado, M. L. Bicalho, E. K. Ganda, S. F. Lima, R. Rossi, B. L. Ribeiro, A. Kussler, and R. C. Bicalho. 2016. Lameness prevalence and risk factors in large dairy farms in upstate New York. Model development for the prediction of claw horn disruption lesions. PLoS One 11:e0146718.

Fujii, J., Y. Iuchi, and F. Okada. 2005. Fundamental roles of reactive oxygen species and protective mechanisms in the female reproductive system. Reprod. Biol. Endocrinol. 3:43.

Fuller, E. A., L. Sominsky, J. M. Sutherland, K. A. Redgrove, L. Harms, E. A. McLaughlin, and D. M. Hodgson. 2017. Neonatal immune activation depletes the ovarian follicle reserve and alters ovarian acute inflammatory mediators in neonatal rats. Biol. Reprod. 97:719-730.

Galvão, K. N., M. Frajblat, W. Butler, S. Brittin, C. Guard, and R. Gilbert. 2010. Effect of early postpartum ovulation on fertility in dairy cows. Reprod. Domest. Anim. 45:e207-e211.

Galvão, K. N., J. E. Santos, S. O. Juchem, R. L. Cerri, A. C. Coscioni, and M. Villasenor. 2004. Effect of addition of a progesterone intravaginal insert to a timed insemination protocol using estradiol cypionate on ovulation rate, pregnancy rate, and late embryonic loss in lactating dairy cows. J. Anim. Sci. 82:3508-3517.

Gilbert, R. O. 2011. The effects of endometritis on the establishment of pregnancy in cattle. Reprod. Fertil. Dev. 24:252-257.

Gilbert, R. O. 2016. Management of reproductive disease in dairy cows. Vet. Clin. North Am. Food Anim. Pract. 32:387-410.

Gilbert, R. O., W. T. Bosu, and A. T. Peter. 1990. The effect of Escherichia coli endotoxin on luteal function in Holstein heifers. Theriogenology 33:645-651.

Gilbert, R. O., and N. R. Santos. 2016. Dynamics of postpartum endometrial cytology and bacteriology and their relationship to fertility in dairy cows. Theriogenology 85:1367-1374.

Goodale, L. F., S. Hayrabedran, K. Todorova, R. Roussev, S. Ramu, C. Stamatkin, C. B. Coulam, E. R. Barnea, and R. O. Gilbert. 2017. Preimplantation factor (PIF) protects cultured embryos against oxidative stress: Relevance for recurrent pregnancy loss (RPL) therapy. Oncotarget 8:32419-32432.

Griffin, J. F., P. J. Hartigan, and W. R. Nunn. 1974a. Non-specific uterine infection and bovine fertility. I. Infection patterns and endometritis during the first seven weeks post-partum. Theriogenology 1:91-106

Griffin, J. F., P. J. Hartigan, and W. R. Nunn. 1974b. Non-specific uterine infection and bovine fertility. II. Infection patterns and endometritis before and after service. Theriogenology 1:107-114.

Gu, B. X., X. Wang, B. L. Yin, H. B. Guo, H. L. Zhang, S. D. Zhang, and C. L. Zhang. 2016. Abnormal expression of TLRs may play a role in lower embryo quality of women with polycystic ovary syndrome. Syst Biol Reprod Med 62:353-358. 
Gümen, A., J. N. Guenther, and M. C. Wiltbank. 2003. Follicular size and response to Ovsynch versus detection of estrus in anovular and ovular lactating dairy cows. J. Dairy Sci. 86:3184-3194.

Haimerl, P., and W. Heuwieser. 2014. Invited review: Antibiotic treatment of metritis in dairy cows: A systematic approach. J. Dairy Sci. 97:6649-6661.

Herath, S., E. J. Williams, S. T. Lilly, R. O. Gilbert, H. Dobson, C. E. Bryant, and I. M. Sheldon. 2007. Ovarian follicular cells have innate immune capabilities that modulate their endocrine function. Reproduction 134:683-693.

Hertl, J. A., Y. T. Grohn, J. D. Leach, D. Bar, G. J. Bennett, R N. Gonzalez, B. J. Rauch, F. L. Welcome, L. W. Tauer, and Y. H. Schukken. 2010. Effects of clinical mastitis caused by grampositive and gram-negative bacteria and other organisms on the probability of conception in New York State Holstein dairy cows. J. Dairy Sci. 93:1551-1560.

Ireland, J. J., G. W. Smith, D. Scheetz, F. Jimenez-Krassel, J. K. Folger, J. L. Ireland, F. Mossa, P. Lonergan, and A. C. Evans. 2011. Does size matter in females? An overview of the impact of the high variation in the ovarian reserve on ovarian function and fertility, utility of anti-Mullerian hormone as a diagnostic marker for fertility and causes of variation in the ovarian reserve in cattle. Reprod. Fertil. Dev. 23:1-14.

Ireland, J. J., A. E. Zielak-Steciwko, F. Jimenez-Krassel, J. Folger, A. Bettegowda, D. Scheetz, S. Walsh, F. Mossa, P. G. Knight, G. W. Smith, P. Lonergan, and A. C. Evans. 2009. Variation in the ovarian reserve is linked to alterations in intrafollicular estradiol production and ovarian biomarkers of follicular differentiation and oocyte quality in cattle. Biol. Reprod. 80:954-964.

Ireland, J. L., D. Scheetz, F. Jimenez-Krassel, A. P. Themmen, F. Ward, P. Lonergan, G. W. Smith, G. I. Perez, A. C. Evans, and J. J. Ireland. 2008. Antral follicle count reliably predicts number of morphologically healthy oocytes and follicles in ovaries of young adult cattle. Biol. Reprod. 79:1219-1225.

Kvidera, S. K., E. A. Horst, M. Abuajamieh, E. J. Mayorga, M. V. Sanz Fernandez, and L. H. Baumgard. 2016. Technical note: A procedure to estimate glucose requirements of an activated immune system in steers. J. Anim. Sci. 94:4591-4599.

Lai, Q., W. Xiang, Q. Li, H. Zhang, Y. Li, G. Zhu, C. Xiong, and L. Jin. 2018. Oxidative stress in granulosa cells contributes to poor oocyte quality and IVF-ET outcomes in women with polycystic ovary syndrome. Front. Med. 12:518-524.

LeBlanc, S. J., T. F. Duffield, K. E. Leslie, K. G. Bateman, G. P. Keefe, J. S. Walton, and W. H. Johnson. 2002. Defining and diagnosing postpartum clinical endometritis and its impact on reproductive performance in dairy cows. J. Dairy Sci. 85:2223-2236.

Lima, F. S., A. Vieira-Neto, G. S. Vasconcellos, R. D. Mingoti, E. Karakaya, E. Sole, R. S. Bisinotto, N. Martinez, C. A. Risco, K N. Galvao, and J. E. Santos. 2014. Efficacy of ampicillin trihydrate or ceftiofur hydrochloride for treatment of metritis and subsequent fertility in dairy cows. J. Dairy Sci. 97:5401-5414.

Loeffler, S. H., M. J. de Vries, Y. H. Schukken, A. C. de Zeeuw, A. A. Dijkhuizen, F. M. de Graaf, and A. Brand. 1999. Use of AI technician scores for body condition, uterine tone and uterine discharge in a model with disease and milk production parameters to predict pregnancy risk at first AI in Holstein dairy cows. Theriogenology 51:1267-1284

Lu, J., Z. Wang, J. Cao, Y. Chen, and Y. Dong. 2018. A novel and compact review on the role of oxidative stress in female reproduction. Reprod. Biol. Endocrinol. 16:80.

Lussier, J. G., P. Matton, and J. J. Dufour. 1987. Growth rates of follicles in the ovary of the cow. J. Reprod. Fertil. 81:301-307.

Machado, V. S., G. Oikonomou, M. L. Bicalho, W. A. Knauer, R. Gilbert, and R. C. Bicalho. 2012. Investigation of postpartum dairy cows' uterine microbial diversity using metagenomic pyrosequencing of the 16S rRNA gene. Vet. Microbiol. 159:460-469.

Magata, F., M. Horiuchi, R. Echizenya, R. Miura, S. Chiba, M. Matsui, A. Miyamoto, Y. Kobayashi, and T. Shimizu. 2014a. Lipopolysaccharide in ovarian follicular fluid influences the steroid production in large follicles of dairy cows. Anim. Reprod. Sci. 144:6-13.
Magata, F., M. Horiuchi, A. Miyamoto, and T. Shimizu. 2014b. Lipopolysaccharide (LPS) inhibits steroid production in theca cells of bovine follicles in vitro: Distinct effect of LPS on theca cell function in pre- and post-selection follicles. J. Reprod. Dev. 60:280-287.

Magata, F., M. Horiuchi, A. Miyamoto, and T. Shimizu. 2014c. Peptidoglycan inhibits progesterone and androstenedione production in bovine ovarian theca cells. Toxicol. In Vitro 28:961-967.

Magata, F., Y. Ishida, A. Miyamoto, H. Furuoka, H. Inokuma, and T. Shimizu. 2015. Comparison of bacterial endotoxin lipopolysaccharide concentrations in the blood, ovarian follicular fluid and uterine fluid: A clinical case of bovine metritis. J. Vet. Med. Sci. $77: 81-84$.

Magata, F., and T. Shimizu. 2017. Effect of lipopolysaccharide on developmental competence of oocytes. Reprod. Toxicol. 71:1-7.

Mapletoft, R. J., M. R. Del Campo, and O. J. Ginther. 1975. Unilateral luteotropic effect of uterine venous effluent of a gravid uterine horn in sheep. Proc. Soc. Exp. Biol. Med. 150:129-133.

Mapletoft, R. J., M. R. Del Campo, and O. J. Ginther. 1976a. Local venoarterial pathway for uterine-induced luteolysis in cows. Proc. Soc. Exp. Biol. Med. 153:289-294.

Mapletoft, R. J., and O. J. Ginther. 1975. Adequacy of main uterine vein and the ovarian artery in the local venoarterial pathway for uterine-induced luteolysis in ewes. Am. J. Vet. Res. 36:957-963.

Mapletoft, R. J., D. R. Lapin, and O. J. Ginther. 1976b. The ovarian artery as the final component of the local luteotropic pathway between a gravid uterine horn and ovary in ewes. Biol. Reprod. 15:414-421.

Monie, T. P., C. E. Bryant, and N. J. Gay. 2009. Activating immunity: Lessons from the TLRs and NLRs. Trends Biochem. Sci 34:553-561.

Moraes, J. G. N., S. K. Behura, T. W. Geary, P. J. Hansen, H. L. Neibergs, and T. E. Spencer. 2018. Uterine influences on conceptus development in fertility-classified animals. Proc. Natl. Acad. Sci USA 115:E1749-E1758.

Neves, R. C., B. M. Leno, M. D. Curler, M. J. Thomas, T. R. Overton, and J. A. A. McArt. 2018. Association of immediate postpartum plasma calcium concentration with early-lactation clinical diseases, culling, reproduction, and milk production in Holstein cows. J. Dairy Sci. 101:547-555.

Oltenacu, P. A., J. H. Britt, R. K. Braun, and R. W. Mellenberger. 1983. Relationships among type of parturition, type of discharge from genital tract, involution of cervix, and subsequent reproductive performance in Holstein cows. J. Dairy Sci. 66:612-619.

Pelzer, E. S., J. A. Allan, M. A. Waterhouse, T. Ross, K. W. Beagley, and C. L. Knox. 2013. Microorganisms within human follicular fluid: Effects on IVF. PLoS One 8:e59062.

Perkins, A. T., T. M. Das, L. C. Panzera, and S. E. Bickel. 2016 Oxidative stress in oocytes during midprophase induces premature loss of cohesion and chromosome segregation errors. Proc. Natl. Acad. Sci. USA 113:E6823-E6830.

Price, J. C., J. J. Bromfield, and I. M. Sheldon. 2013. Pathogenassociated molecular patterns initiate inflammation and perturb the endocrine function of bovine granulosa cells from ovarian dominant follicles via TLR2 and TLR4 pathways. Endocrinology 154:3377-3386.

Rahiminejad, M. E., A. Moaddab, M. Ganji, N. Eskandari, M. Yepez, S. Rabiee, M. Wise, R. Ruano, and A. Ranjbar. 2016. Oxidative stress biomarkers in endometrial secretions: A comparison between successful and unsuccessful in vitro fertilization cycles. J. Reprod. Immunol. 116:70-75

Reynolds, K. A., A. L. Boudoures, M. M. Chi, Q. Wang, and K. H. Moley. 2015. Adverse effects of obesity and/or high-fat diet on oocyte quality and metabolism are not reversible with resumption of regular diet in mice. Reprod. Fertil. Dev. 27:716-724.

Ribeiro, E. S., G. Gomes, L. F. Greco, R. L. A. Cerri, A. Vieira-Neto, P. L. J. Monteiro Jr., F. S. Lima, R. S. Bisinotto, W. W. Thatcher, and J. E. P. Santos. 2016. Carryover effect of postpartum inflammatory diseases on developmental biology and fertility in lactating dairy cows. J. Dairy Sci. 99:2201-2220. 
Ribeiro, E. S., F. S. Lima, L. F. Greco, R. S. Bisinotto, A. P. Monteiro, M. Favoreto, H. Ayres, R. S. Marsola, N. Martinez, W. W. Thatcher, and J. E. Santos. 2013. Prevalence of periparturient diseases and effects on fertility of seasonally calving grazing dairy cows supplemented with concentrates. J. Dairy Sci. 96:5682-5697.

Risco, C. A., G. A. Donovan, and J. Hernandez. 1999. Clinical mastitis associated with abortion in dairy cows. J. Dairy Sci. 82:1684-1689.

Santos, J. E., R. S. Bisinotto, and E. S. Ribeiro. 2016. Mechanisms underlying reduced fertility in anovular dairy cows. Theriogenology 86:254-262.

Santos, J. E., S. O. Juchem, R. L. Cerri, K. N. Galvão, R. C. Chebel, W. W. Thatcher, C. S. Dei, and C. R. Bilby. 2004a. Effect of bST and reproductive management on reproductive performance of Holstein dairy cows. J. Dairy Sci. 87:868-881.

Santos, J. E., W. W. Thatcher, R. C. Chebel, R. L. Cerri, and K. N. Galvão. 2004b. The effect of embryonic death rates in cattle on the efficacy of estrus synchronization programs. Anim. Reprod. Sci. 82-83:513-535.

Santos, J. E. P., and E. S. Ribeiro. 2014. Impact of animal health on reproduction in dairy cows. Anim. Reprod. 11:254-269.

Santos, T. M., R. O. Gilbert, and R. C. Bicalho. 2011. Metagenomic analysis of the uterine bacterial microbiota in healthy and metritic postpartum dairy cows. J. Dairy Sci. 94:291-302.

Sawyer, H. R., P. Smith, D. A. Heath, J. L. Juengel, S. J. Wakefield, and K. P. McNatty. 2002. Formation of ovarian follicles during fetal development in sheep. Biol. Reprod. 66:1134-1150.

Scaramuzzi, R. J., D. T. Baird, B. K. Campbell, M. A. Driancourt, J. Dupont, J. E. Fortune, R. B. Gilchrist, G. B. Martin, K. P. McNatty, A. S. McNeilly, P. Monget, D. Monniaux, C. Vinoles, and R. Webb. 2011. Regulation of folliculogenesis and the determination of ovulation rate in ruminants. Reprod. Fertil. Dev. 23:444-467.

Shams-Esfandabadi, N., A. Shirazi, and H. Ghasemzadeh-Nava. 2004. Pregnancy rate following post-insemination intrauterine treatment of endometritis in dairy cattle. J. Vet. Med. A Physiol. Pathol. Clin. Med. 51:155-156.

Sheldon, I. M., D. E. Noakes, A. N. Rycroft, D. U. Pfeiffer, and H. Dobson. 2002. Influence of uterine bacterial contamination after parturition on ovarian dominant follicle selection and follicle growth and function in cattle. Reproduction 123:837-845.

Sheldon, I. M., S. B. Price, J. Cronin, R. O. Gilbert, and J. E. Gadsby. 2009. Mechanisms of infertility associated with clinical and subclinical endometritis in high producing dairy cattle. Reprod. Domest. Anim. 44:1-9.

Sheldon, I. M., A. N. Rycroft, B. Dogan, M. Craven, J. J. Bromfield, A. Chandler, M. H. Roberts, S. B. Price, R. O. Gilbert, and K. W. Simpson. 2010. Specific strains of Escherichia coli are pathogenic for the endometrium of cattle and cause pelvic inflammatory disease in cattle and mice. PLoS One 5:e9192.

Sheldon, I. M., A. N. Rycroft, and C. Zhou. 2004. Association between postpartum pyrexia and uterine bacterial infection in dairy cattle. Vet. Rec. 154:289-293.
Sicsic, R., T. Goshen, R. Dutta, N. Kedem-Vaanunu, V. KaplanShabtai, Z. Pasternak, Y. Gottlieb, N. Y. Shpigel, and T. Raz. 2018. Microbial communities and inflammatory response in the endometrium differ between normal and metritic dairy cows at 5-10 days post-partum. Vet. Res. 49:77.

Sominsky, L., E. A. Fuller, and D. M. Hodgson. 2015. Factors in early-life programming of reproductive fitness. Neuroendocrinology 102:216-225.

Sterry, R. A., M. L. Welle, and P. M. Fricke. 2006. Treatment with gonadotropin-releasing hormone after first timed artificial insemination improves fertility in noncycling lactating dairy cows. J. Dairy Sci. 89:4237-4245.

Sutton-McDowall, M. L., L. L. Wu, M. Purdey, A. D. Abell, E. M. Goldys, K. L. MacMillan, J. G. Thompson, and R. L. Robker. 2016. Nonesterified fatty acid-induced endoplasmic reticulum stress in cattle cumulus oocyte complexes alters cell metabolism and developmental competence. Biol. Reprod. 94:23.

Swain, J. E., and T. B. Pool. 2008. ART failure: Oocyte contributions to unsuccessful fertilization. Hum. Reprod. Update 14:431-446.

Valacchi, G., F. Virgili, C. Cervellati, and A. Pecorelli. 2018. OxInflammation: From subclinical condition to pathological biomarker. Front. Physiol. 9:858.

Vannuccini, S., V. L. Clifton, I. S. Fraser, H. S. Taylor, H. Critchley, L. C. Giudice, and F. Petraglia. 2016. Infertility and reproductive disorders: Impact of hormonal and inflammatory mechanisms on pregnancy outcome. Hum. Reprod. Update 22:104-115.

Vieira-Neto, A., R. O. Gilbert, W. R. Butler, J. E. P. Santos, E. S. Ribeiro, M. M. Vercouteren, R. G. Bruno, J. H. J. Bittar, and K. N. Galvao. 2014. Individual and combined effects of anovulation and cytological endometritis on reproductive performance of dairy cows. J. Dairy Sci. 97:5415-5425.

Walsh, R. B., D. F. Kelton, T. F. Duffield, K. E. Leslie, J. S. Walton, and S. J. LeBlanc. 2007. Prevalence and risk factors for postpartum anovulatory condition in dairy cows. J. Dairy Sci. 90:315-324.

Williams, E. J., D. P. Fischer, D. E. Noakes, G. C. England, A. Rycroft, H. Dobson, and I. M. Sheldon. 2007. The relationship between uterine pathogen growth density and ovarian function in the postpartum dairy cow. Theriogenology 68:549-559.

Wilson, D. J., Y. T. Grohn, G. J. Bennett, R. N. Gonzalez, Y. H. Schukken, and J. Spatz. 2008. Milk production change following clinical mastitis and reproductive performance compared among J5 vaccinated and control dairy cattle. J. Dairy Sci. 91:3869-3879.

Wiltbank, M. C., G. M. Baez, A. Garcia-Guerra, M. Z. Toledo, P. L. Monteiro, L. F. Melo, J. C. Ochoa, J. E. Santos, and R. Sartori. 2016. Pivotal periods for pregnancy loss during the first trimester of gestation in lactating dairy cows. Theriogenology 86:239-253. 